Revista de Ciencias Sociales - Número 65 (2014) - Páginas 89-120

Reconocimiento y responsabilidad moral. A propósito de la teoría...

\title{
RECONOCIMIENTO Y RESPONSABILIDAD MORAL A PROPÓSITO DE LA TEORÍA DEL RECONOCIMIENTO DE CHARLES TAYLOR
}

\author{
RECOGNITION AND MORAL RESPONSIBILITY \\ ABOUT THE THEORY OF RECOGNITION \\ OF CHARLES TAYLOR
}

\author{
ESTEBAN PEREIRA FREDES* \\ Facultad de Derecho \\ Universidad Adolfo Ibáñez, Chile \\ esteban.pereira@uai.cl
}

\section{Resumen}

El artículo analiza en forma crítica la teoría del reconocimiento de Charles Taylor, esgrimida por el autor canadiense en su influyente ensayo de 1994 "The Politics of Recognition". Se reconstruye la tesis de Taylor bajo el contexto general de su filosofía, evaluando su rendimiento explicativo a la luz del cúmulo de observaciones críticas generadas por su propuesta. Se enfatiza

* Profesor Instructor. Agradezco las observaciones que efectuaron a una versión preliminar de este trabajo los profesores Juan Ormeño Karzulovic y Nicolás del Valle Orellana. Una parte sustantiva de las consideraciones que aquí se esgrimen son tributarias de las discusiones analizadas bajo el curso "Lucha por el reconocimiento: alcances filosófico-sociales", impartido por ambos profesores en el marco del Magíster en Pensamiento Contemporáneo: Filosofía y Pensamiento Político del Instituto de Humanidades de la Universidad Diego Portales, durante el segundo semestre de 2013. Artículo recibido el 25 de agosto de 2014 y aceptado el 5 de octubre de 2014.

Revista de Ciencias Sociales - Número 65 (2014) - Universidad de Valparáíso - ISSN 0716-7725-Valparaíso, Chile 
la necesidad de robustecer a la noción de reconocimiento mediante un término dotado de dimensiones normativas, tal como el concepto de responsabilidad moral. Dado el escenario políticamente conflictivo en que se verifican las disputas por el reconocimiento, conviene conciliar a la política del reconocimiento con la implicación de los individuos en contextos de participación intersubjetiva, ratificando su participación en los asuntos públicos como agentes moralmente responsables de sus acciones y planes de vida.

\section{Palabras claves}

Teoría del reconocimiento, identidad, responsabilidad moral, Charles Taylor, P.F. Strawson.

\section{Abstract}

The article critically examines the theory of recognition of Charles Taylor, put forward by the Canadian author in his influential essay of 1994 “The Politics of Recognition". Taylor's thesis is reconstructed under the general context of his philosophy, evaluating its explanatory performance against the cluster of critiques generated by the proposal. The need is emphasized, to strengthen the notion of recognition by a notion possessing normative dimensions, such as the concept of moral responsibility. Given the politically conflictive setting in which disputes for recognition take place, the politics of recognition should be reconciled with the involvement of individuals in contexts of intersubjective participation, thus confirming their participation in public affairs as agents morally responsible for their actions and plans of life.

\section{Keywords}

Theory of recognition, identity, moral responsibility, Charles Taylor, P.F. Strawson.

\section{Introducción}

Durante el presente año se cumplen veinte años desde que fuere publicado en 1994 el ensayo de Charles Taylor, titulado originalmente como ¿The Politics of Recognition. Como sabemos, dicho texto alcanzó una significativa repercusión en las discusiones sobre multiculturalismo, liberalismo y derechos de minorías, transformándose en una lectura

Facultad de Derecho y Ciencias Sociales - Universidad de Valparaíso - Chile 
obligada de la generosa obra del nacido en Montreal. Por supuesto, sus ideas abrieron diversos flancos de críticas, pero un número no menor de estos cuestionamientos desatendió consideraciones cruciales sobre la configuración del yo moderno bajo el ideal de la autenticidad, defendidas en el grueso de las investigaciones de Taylor. En lo que sigue, analizaré la teoría del reconocimiento formulada por Charles Taylor, evaluándola a la luz de la fecunda discusión que es tributaria de su posición. Finalmente, examinaré en forma crítica la pertinencia de la discusión sobre el reconocimiento, sugiriendo robustecer este término a partir de las dimensiones normativas y políticas que es posible extraer de la responsabilidad moral.

En la segunda sección, desarrollaré la teoría sobre el reconocimiento esgrimida por Taylor, considerando el cúmulo de elementos conceptuales en los cuales se inserta esta tesis bajo su pensamiento filosófico.

En la tercera sección, presentaré algunos diagnósticos críticos que respecto de la propuesta de Taylor se han planteado en la filosofía de la política contemporánea. Tales exámenes se articularán bajo dos órdenes de consideraciones: teórico-políticos y conceptuales.

En la cuarta sección, se evaluará críticamente la pertinencia de la discusión sobre el reconocimiento, a la luz del potencial explicativo de la noción responsabilidad moral para la conformación de la identidad personal y su relevancia en las disputas por el reconocimiento en los asuntos públicos. Sostendré que las deficiencias normativas y políticoeconómicas que presenta la noción de reconocimiento, pudieren enfrentarse de forma satisfactoria mediante su reinterpretación a partir de las dimensiones y exigencias a las cuales apela la responsabilidad moral en la esfera privada y pública.

\section{El reconocimiento y sus políticas}

La influyente conferencia del autor canadiense La política del reconocimiento, trazó buena parte de las líneas del debate contemporáneo acerca del reconocimiento. ${ }^{1}$ El término reconocimiento

1. Para diversas evaluaciones sobre el desarrollo e influencias de la teoría del reconocimiento en la filosofía contemporánea, véase la compilación de SCHMIDT am Busch, Hans-Christoph y ZURN, Christopher F. (eds.): The

Revista de Ciencias Sociales - Número 65 (2014) - Universidad de Valparáíso - ISSN 0716-7725-Valparáiso, Chile 
fue rápidamente asimilado como uno de los tópicos más llamativos del pensamiento de quien, al igual que su maestro Isaiah Berlin, llegó a ser Chichele Professor de teoría social y política en Oxford. De modo que la selección de la tesis de Taylor se explica en virtud de la significativa influencia que ella ha tenido en esta discusión. Al respecto, Taylor presenta una aproximación al problema según la cual el reconocimiento tendría una relación analítica con la identidad, existiendo distintos modelos de comprensión política que se encuentran en disputa para dar cuenta del reconocimiento, asociados a las teorías liberales de corte universalista y las políticas de la diferencia.

El interés de Taylor por el reconocimiento se devela en términos de su vinculación con la noción de identidad. La identidad para el autor admite ribetes metafísicos y éticos, ya que nos indica qué somos, qué hacemos y qué deberíamos ser. De modo que si bien el reconocimiento se evidencia en nuestras prácticas normativas, expresa la comprensión que tenemos de nosotros mismos, asumiendo que tal comprensión está definida por la imagen que el otro posee de uno. Detrás de las prácticas de reconocimiento recíproco se sitúan exigencias básicas y constituyentes de lo humano. Así, “[e]l reconocimiento debido no sólo es una cortesía que debemos a los demás: es una necesidad humana vital"2. Como sabemos, la obra de Taylor se encuentra influenciada por las contribuciones esgrimidas por la filosofía analítica en relación a la relevancia del lenguaje en los asuntos filosóficos ${ }^{3}$. De modo que no ha

Philosophy of Recognition: Historical and Contemporary Perspectives. Lexington Books, Plymouth, 2010. Una colección cuyo hincapié se centra en la conexión entre las teorías sobre el reconocimiento inspiradas por Hegel y la ontología social analítica, en IKÄHEIMO, Heikki y \& LAITINEN, Arto (eds.): Recognition and Social Ontology. Brill, Leiden-Boston, 2011.

2. TAYLOR, Charles: El multiculturalismo y "la política del reconocimiento". Fondo de Cultura Económica, México D.F., 2003. (Trad. Mónica Utrilla de Neira). Págs. 54-55.

3. Sin embargo, el propio Taylor atribuye a Johann Gottfried von Herder la importancia de formular la teoría expresivista del lenguaje, que revolucionaría nuestra concepción sobre el lenguaje y el significado. De igual modo, hay que tener presente que dicha interpretación se asocia a la reconstrucción que la historia de las

Facultad de Derecho y Ciencias Sociales - Universidad de Valparaíso - Chile 
de extrañar que en la concepción suscrita por Taylor sobre la identidad se entrelacen consideraciones distintivas de la tradición analítica de la filosofía ${ }^{4}$.

De ahí que su noción de identidad se distancie de versiones únicamente metafísicas o especulativas características de tradiciones filosóficas del siglo XIX, adoptando una perspectiva lingüística y hermenéutica de la actividad involucrada al definir nuestra identidad. Para Taylor, la identidad consiste en una "[...] interpretación que hace una persona de quién es y de sus características definitorias fundamentales como ser humano" 5 . Es decir, la formación de la identidad se encuentra asociada a un complejo ejercicio de autocomprensión del sujeto. Tal actividad se entiende bajo un esquema hermenéutico que efectúa el individuo pero cuyo sentido está determinado por su interacción con los otros sujetos. Bajo tales términos, la identidad sugiere dimensiones intersubjetivas y ahí descansa la relevancia teórica del reconocimiento.

Si nuestra identidad se moldea por el reconocimiento de otros, se sigue que también es distorsionada por el déficit de reconocimiento o bien por lo que el autor denomina como falso reconocimiento. Mientras la falta de reconocimiento necesariamente provoca un daño

ideas de corte analítico, también desarrolló sobre los trabajos de Herder, a partir de las contribuciones de Isaiah Berlin. Sobre este punto puede consultarse, TAYLOR, Charles: Argumentos filosóficos. Ensayos sobre el conocimiento, el lenguaje y la modernidad. Paidós, Barcelona, 1997. (Trad. Fina Birulés Bertrán). Págs. 115-141.

4. La diversidad de concepciones que conviven en el seno de la tradición analítica de la filosofía puede revisarse en ORELLANA Benado, M. E.: "Tradiciones y concepciones en filosofía”. En: Nudler, Oscar (ed.): Filosofía de la filosofía. Enciclopedia Iberoamericana de Filosofía, No 31. Trotta, Madrid, 2010. Págs. 49-78. Según se sugiere por el autor, los estudios de Isaiah Berlin permitieron configurar una concepción sobre la filosofía distinta a las vertientes del cientificismo y lenguaje cotidiano en el escenario analítico. Se consideró como indispensable el desarrollo de trabajos históricos y reconstrucciones intelectuales, a partir de los estudios sobre nuestros conceptos y prácticas lingüísticas cotidianas. Taylor replica esta sugerencia berliniana.

5. TAYLOR, Charles: El multiculturalismo y "la política del reconocimiento". Ob. cit. Pág. 53.

Revista de Ciencias Sociales - Número 65 (2014) - Universidad de Valparáíso - ISSN 0716-7725-Valparaíso, Chile 
en la identidad del agente no reconocido por los otros, el falso reconocimiento supone una falta del debido respeto que nos debemos unos a otros. De modo que "[e]l falso reconocimiento o la falta de reconocimiento puede causar daño, puede ser una forma de opresión que aprisione a alguien en un modo de ser falso, deformado y reducido"6. Es interesante observar que el reconocimiento y su falsa modalidad están conceptuados en torno al objeto del reconocimiento o noreconocimiento. El centro de la preocupación de Taylor no parece estar situado en la actividad del reconocimiento sino en los efectos que su presencia o ausencia genere en la identidad humana ${ }^{7}$.

El problema del reconocimiento goza de un valor epistémico moderno. Aquello se explica porque sólo en la modernidad tuvo lugar el reemplazo conceptual entre las categorías de honor y dignidad. El término honor se encuentra vinculado a un sistema de jerarquías, preferencias y diferencias definitorias del modelo pre-ilustrado de sociedad y, en cambio, la dignidad apela a una categoría universal de tratamiento normativo acerca de los seres humanos. La dignidad es predicada del ser racional universalmente considerado, sin diferenciaciones y resguardando la simetría entre unos y otros. Por supuesto, la tesis tayloriana hace suyas las observaciones sobre la relevancia de la noción de dignidad para la construcción de lo humano esgrimidas bajo el pensamiento kantiano ${ }^{8}$.

De igual manera, si las exigencias por el reconocimiento son recientes, la configuración de la posición normativa que lo sustenta

6. Ibíd. Pág. 54.

7. De acuerdo a Juan Ormeño, “[...] lo que en su conferencia parece determinante no es tanto el acto mismo del reconocer, sino aquello que debe ser reconocido". Véase, ORMEÑO, Juan: "Conflicto, convergencia y reconocimiento". En: Revista Laguna, No 16, 2005. Pág. 150.

8. Para el filósofo de Königsberg, el término dignidad resulta indispensable para comprender la vinculación entre el sujeto racional y la legislación universal. Según Kant, "[...] la dignidad de la humanidad consiste justo en esa capacidad para dar leyes universales, aunque con la condición de quedar sometida ella misma a esa legislación”. KANT, Immanuel: Fundamentación para una metafísica de las costumbres. Alianza, Madrid, 2002. (Trad. Roberto Rodríguez Aramayo). Pág. 131.

Facultad de Derecho y Ciencias Sociales - Universidad de Valparaíso - Chile 
también lo es. Según Taylor, en la modernidad se instala un nuevo ideal ético relativo a problematizar la pregunta sobre cómo debemos vivir, que se encuentra constituido por el ideal de autenticidad. Esta posición permitiría robustecer a la política del reconocimiento a través de un insumo valorativo. La ética de la autenticidad no se encuentra conceptualmente clausurada en este ensayo, pero se despliega a partir de un conjunto de proposiciones ${ }^{9}$. Aquella supondría afirmar que el ser genérico se define según su singular individualidad, de modo que el agente procura mantener en su comportamiento una fidelidad a sí mismo y refinar su sentido moral interior. Es decir, abandona su actuar según un mero cálculo estratégico de consecuencias, optando por sostener una obediencia a sus deseos y sentimientos. En otro lugar, en tanto, el ideal de la autenticidad ha sido tematizado de acuerdo a los siguientes términos: "[e]xiste cierta forma de ser humano que constituye mi propia forma. Estoy destinado a vivir mi vida de esa forma, y no a imitación de la de ningún otro. Pero con ello se concede importancia al hecho de ser fiel a uno mismo. Si no lo soy pierdo de vista la clave de mi vida, y lo que significa ser humano para mi" ${ }^{10}$.

Según lo indiqué, el enfoque de Taylor sobre el reconocimiento se encuentra justificado por la influencia que esta actividad interpretativa tiene en la conformación de nuestra identidad. Y tal proceso se inserta bajo el contexto de una posición valorativa que radica en el ideal de autenticidad. De acuerdo a tales consideraciones, la tesis del reconocimiento está irremediablemente conectada con dimensiones normativas, en atención a que la racionalidad que mejor lo explica es

9. Un resumen del ideal que la autenticidad proclama es deslizado en palabras de Taylor: "[...] podemos afirmar que la autenticidad (A) entraña (i) creación y construcción así como descubrimiento, (ii) originalidad, y con frecuencia (iii) oposición a las reglas de la sociedad e incluso, en potencia, a aquello que reconocemos como moralidad. Pero también es cierto, como ya vimos, que (B) requiere (i) apertura a horizontes de significado (pues de otro modo la creación pierde el trasfondo que puede salvarla de insignificancia) y (ii) una autodefinición en el diálogo”. TAYLOR, Charles: La ética de la autenticidad. Paidós, Barcelona, 1994. (Trad. Pablo Carbajosa Pérez). Pág. 99. Cursivas del original.

10. Ibíd. Págs. 54-65. Cursivas del original.

Revista de Ciencias Sociales - Número 65 (2014) - Universidad de Valparáíso - ISSN 0716-7725-Valparaíso, Chile 
un modelo dialógico en oposición a un esquema rival monológico ${ }^{11}$. Bajo el prisma monológico, la identidad se podría formar gracias al despliegue del propio sujeto, de manera desvinculada del mundo del cual forma parte. Gozamos de suficiencia para conformar nuestra identidad. A su vez, el prisma dialógico sugiere que nos realizamos y comprendemos dialógicamente a través de nuestro intercambio con los demás (y conmigo mismo). La autorrealización de nuestra identidad depende de las relaciones con los demás y de ahí que la negociación intersubjetiva requiera del mutuo reconocimiento. Nuestra identidad en particular y la moralidad en general dependen en buena medida de nuestra participación y relación con los demás miembros de la comunidad.

La política del reconocimiento planteada por Taylor en los términos de posibilitar el recíproco reconocimiento de nuestras identidades y formulada mediante una racionalidad intersubjetiva, ha sido recepcionada mediante dos esquemas de comprensión en disputa. Por una parte, un modelo universalista y, por otra, el modelo de las políticas de la diferencia. Mientras el modelo universalista propone un reconocimiento genérico a partir de la formulación de un catálogo de derechos y obligaciones correlativos que son reconocidos para uno y todos los individuos, a quienes se les atribuye dignidad como justificación de su estatus normativo, el esquema de las políticas de la diferencia defiende un reconocimiento único y original en que cada individuo y comunidad cuenta. Rechaza la alternativa liberal de diseñar un reconocimiento mediante catálogos de derechos, promoviendo alzar la identidad distintiva y propia que le pertenece a cada sujeto o comunidad para evitar que sea homogenizada por ciertas comunidades hegemónicas. La universalidad del primero es sustituida por la autenticidad del segundo.

A partir de tales observaciones, la noción de reconocimiento se encuentra en disputa por las políticas que sobre el forjamiento mutuo

11. Un diseño dialógico de racionalidad contrapuesto a una visión monológica clásicamente asociada al esquema cartesiano, se encuentra explícitamente desarrollado en HABERMAS, Jürgen: Teoría de la acción comunicativa. Tomo I. Racionalidad de la acción y racionalización social. Taurus, Madrid, 1987. (Trad. Manuel Jiménez Redondo). Págs. 24-43.

Facultad de Derecho y Ciencias Sociales - Universidad de Valparaíso - Chile 
de la identidad ha esgrimido tanto el liberalismo político y, podríamos reducir a la doctrina rival con ausencia de precisiones, en el comunitarismo. Desde luego, el examen preliminar de ambas interpretaciones deviene en la incompatibilidad de las propuestas. Sin embargo, la política de Taylor sugiere conciliarlas para dar cuenta de una postura mediadora en que la dignidad universal estimule un reconocimiento de la especificidad. Piensa el autor en una política en que la “[...] demanda universal impele a un reconocimiento de la especificidad"12. De manera que si todos poseen una identidad propia, es razonable conocer universalmente la peculiar identidad de cada quien ${ }^{13}$.

No obstante ambas lecturas del reconocimiento se fundamentan en intuiciones metafísicas también conflictivas entre sí. El universalismo afirma la igualdad en el mutuo respeto por constituir seres racionales regulados por principios comunes y universales, incurriendo teóricamente en la homogeneización y pragmáticamente en una contradicción; a saber deviene en un particularismo disfrazado de universalismo, ya que favorece y universaliza a ciertas identidades o rasgos específicos considerados como privilegiados, en base a un aparente discurso de igualdad $^{14}$. La multiculturalidad, por su parte, sugiere buscar la potencialidad de la empresa en la autodeterminación de la propia identidad, ya sea individual o cultural, pero incurre en una transgresión del principio de no discriminación, que suele considerarse como un estándar normativo en el diseño de nuestras instituciones políticas.

Ahora bien, ¿̇cuál sería la política del reconocimiento formulada por Taylor? Si bien se podría pensar que bajo tal escenario, Taylor no debiere haber tomado partido por alguna de las tesis en disputa, efectivamente lo hace al situar su desafío en formular un liberalismo que no sea un particularismo disfrazado de universalismo. En términos

12. TAYLOR, Charles: El multiculturalismo y "la política del reconocimiento". Ob. cit. Pág. 71.

13. CORREA, Matías: "Sobre Charles Taylor y algunos problemas relativos a la política del reconocimiento”. En: Ars Boni et Aequi, No 5, 2009. Pág. 171.

14. TAYLOR, Charles: El multiculturalismo y "la política del reconocimiento”. Ob. cit. Pág. 78.

Revista de Ciencias Sociales - Número 65 (2014) - Universidad de Valparáíso - ISSN 0716-7725-Valparaíso, Chile 
del profesor de la McGill University, su propósito es transparentar la pertinencia de una teoría liberal que configure una sociedad que adscriba a compromisos morales sustantivos y no sólo de carácter procedimental. El compromiso sustantivo descansaría en el respeto y promoción de la supervivencia de las identidades coexistentes bajo el seno de la sociedad liberal. Tal como ocurre con las demandas colectivas formuladas por la comunidad francófona de Quebec en Canadá ${ }^{15}$. Todo grupo promueve legítimamente una meta colectiva de supervivencia, respecto a la cual ejercen un derecho a su reconocimiento siempre que no exista una violación a derechos de índole sustantiva o procedimental de la comunidad.

De manera que la tensión entre las políticas se disuelve en un liberalismo sustancialmente comprometido con ciertos fines colectivos, esto es, en base a un liberalismo comunitario. No resulta baladí que Taylor conciba que la condición de posibilidad del reconocimiento se exprese en términos de la política liberal, aunque se trate de una versión más sofisticada y sensible a las diferencias. De ahí que Michael Walzer, en su comentario al clásico ensayo de Taylor, lo califique de un "Liberalismo 2" ${ }^{\prime 16}$. Nuestro diseño institucional debe estar compro-

15. No obstante, hay que considerar que existen comunidades frente a las cuales resulta más complejo traspalar los deberes de reconocimiento, que Taylor predica de nuestra existencia bajo un contexto social e interpersonal. Siguiendo a Matías Correa, las doctrinas del islamismo se fundamentan en la conexión necesaria entre política y religión, de manera que difícilmente el liberalismo caracterizado por su proclama de secularización del Estado y espacio público podrá resultar un terreno fértil para el reconocimiento entre comunidades musulmanas y occidentales. Al respecto, véase, CORREA, Matías. Ob. cit. Págs. 177-178. Desde luego, puede ocurrir que una determinada comunidad simplemente no se encuentre interesada en ser objeto del reconocimiento, en circunstancias que Taylor parece presuponer que ello debiere presentarse por el hecho de formar parte de una comunidad lingüística intersubjetiva.

16. Según Walzer, "[e]l segundo tipo de liberalismo permite un Estado comprometido con la supervivencia y el florecimiento de una nación, cultura o religión en particular, o de un (limitado) conjunto de naciones, culturas y religiones, en la medida en que los derechos básicos de los ciudadanos que tienen diferentes compromisos, o que no los tienen en absoluto, estén protegidos”. Véase, WALZER, Michael: "Comentario". En: Taylor Charles: El multiculturalismo y "la política del reconocimiento". Fondo de Cultura Económica, México D.F., 2003. (Trad. Mónica Utrilla de Neira). Págs. 139-140.

Facultad de Derecho y Ciencias Sociales - Universidad de Valparaíso - Chile 
metido con el florecimiento de las distintas identidades forjadas en su interior, en la medida que los ciudadanos que sostienen distintos compromisos, así como quienes no los suscriban, reciban una adecuada protección de sus derechos. La neutralidad liberal es sensible a las diversas concepciones acerca de lo bueno, comprometiéndose al respeto del desenvolvimiento de las identidades en que aquellas se expresan. Como se podrá apreciar, bajo estos términos, el liberalismo logra desplazar la objeción según la cual aquel homogeniza la diferencia, resultando menos liberal, pero sin dejar de constituir un liberalismo.

Sin embargo, al liberalismo político atenuado de Taylor le resta por sortear una valla más fuerte. La ceguera ante la diferencia que muestra el liberalismo devela que este se encuentra incapacitado para constituirse como un escenario político imparcial, bajo el cual pueden coexistir armónicamente los integrantes de distintas culturas. En términos de Taylor, "[t]odo esto equivale a decir que el liberalismo no puede ni debe atribuirse una completa neutralidad cultural. El liberalismo es también un credo combatiente" ${ }^{17}$. Pese a que en el liberalismo convivan diferentes concepciones sobre lo bueno, coexistiendo diversas identidades y formas de vida, según fue advertido con anterioridad, de aquello no se sigue que todos reconozcamos igualmente el valor de cada una de ellas. Existen identidades que selectivamente son privilegiadas por el pensamiento liberal y, a su vez, otras formas de vida que son combatidas y paulatinamente excluidas de los asuntos públicos por la verdadera política liberal.

Sobre este punto, la alegación de Taylor radica en sostener que el valor en virtud del cual las comunidades pueden reclamar el reconocimiento de su identidad no está circunscrito en una mera caridad cultural, porque la cultura no-hegemónica reclama respeto y no un gesto de condescendencia, sino que en una fusión de horizontes. La posibilidad del reconocimiento se juega en una necesaria articulación recíproca entre los legítimos horizontes de las distintas culturas. Al negarnos a fundamentar y ampliar nuestro propio horizonte, negamos la igualdad de respeto o valor por las culturas no-hegemónicas.

17. TAYLOR, Charles: El multiculturalismo y “la política del reconocimiento”. Ob. cit. Pág. 102.

Revista de Ciencias Sociales - Número 65 (2014) - Universidad de Valparáíso - ISSN 0716-7725-Valparáiso, Chile 
Nuevamente el reconocimiento se expresa en un cúmulo de relaciones intersubjetivas que cobran dimensiones normativas, predicando corrección de aquellas conductas que tiendan a tal encuentro de mutuos horizontes e incorrección de los comportamientos que obstaculicen tal concatenación de intereses y formas de vida.

De acuerdo a las consideraciones anteriores, la actividad intersubjetiva de mutua formación de la identidad, bajo la cual estaba situada la comprensión inicial de Taylor sobre el reconocimiento, se desenvuelve ulteriormente en un discurso político liberal que pretende defender la supervivencia de las particularidades y promover la conjugación de los distintos horizontes desplegados por las identidades culturales. De modo de configurar un espacio recíproco de convivencia, respeto y negociación no-hegemónica, sobre la base de la observancia de los derechos básicos de la comunidad liberal. En la próxima sección, se desarrollarán ciertas dificultades que enfrenta la aproximación de Charles Taylor sobre el reconocimiento.

\section{Taylor y sus críticos}

Evaluar la pertinencia explicativa de la tesis de Taylor implica dar cuenta del generoso espectro de comentarios formulados sobre su conocida intervención en el debate. Para efectos de limitar la extensión de este trabajo, y de conformidad a lo que se expondrá en la tercera sección, delimitaré el análisis en dos órdenes de consideraciones críticas. En primer lugar, las evaluaciones teórico-políticas y, en segundo lugar, algunos exámenes conceptuales generados a partir de su teoría del reconocimiento en la filosofía de la política contemporánea.

Desde la primera esfera de consideraciones, pareciera indubitado que Taylor acierta en sostener la tesis según la cual la constitución intersubjetiva de la identidad se alcanza mediante prácticas morales de carácter dialógico entre los distintos miembros de la comunidad. No obstante, deja abiertas profundas problemáticas asociadas a las implicancias que se siguen desde sus presupuestos ontológicos a las políticas de la identidad y la diferencia. Como lo indica Seyla Benhabib, en Taylor existe "[...] una equiparación riesgosa entre ontología y

Facultad de Derecho y Ciencias Sociales - Universidad de Valparaíso - Chile 
propugnación”18. Según Benhabib, existe una utilización ambigua del término reconocimiento en el planteamiento tayloriano, gracias al cual se confunde el plano individual y el colectivo. Taylor presupone que las reivindicaciones individuales de autenticidad son consistentes con aspiraciones colectivas de reconocimiento cultural, pero en ocasiones suelen incluso contradecirse. Existen reivindicaciones incompatibles que ciertas colectividades pueden exigirle a un individuo en su lucha por el reconocimiento de identidades de carácter grupal, como ocurría con la tensión entre las metas de los movimientos nacionalistas y feministas ${ }^{19}$. El yerro de asimilar las reivindicaciones individuales y colectivas, conlleva una peligrosa consideración política: “[...] subordina la autonomía moral a los movimientos por la identidad colectiva" ${ }^{20}$. Taylor articularía la relación entre autenticidad y autonomía en los términos inversos, derivando la identidad colectiva de la expresión auténtica de sí mismo, cuando modernamente el derecho a la expresión de la propia identidad auténtica deriva de la búsqueda autónoma de una buena vida de autoexpresión colectiva.

También esta política del reconocimiento que se alza sobre complejos lingüísticos de interlocución funciona a nivel descriptivo y no necesariamente normativo. La tesis de Taylor explica que las identidades humanas se constituyen en un plano lingüístico y discursivo, pero se mantiene silente respecto a determinar "[...] cuáles de estas redes de interlocución deberían ser privilegiadas como la norma, bajo qué circunstancias y por quiénes" ${ }^{21}$. El liberalismo comunitario propuesto por Taylor tiene el deber de fomentar el encuentro entre horizontes culturales, pero carecemos de insumos teóricos para determinar qué

18. BENHABIB, Seyla: “¿De la redistribución al reconocimiento? El cambio de paradigma de la política contemporánea”. En: Las Reivindicaciones de la Cultura. Igualdad y diversidad en la era global. Katz, Madrid, 2006. (Trad. Alejandra Vassallo). Pág. 97.
19. Ibíd. Pág. 101.
20. Ídem.
21. Ibíd. Pág. 106. Cursivas del original.

Revista de Ciencias Sociales - Número 65 (2014) - Universidad de Valparaíso - ISSN 0716-7725-Valparaíso, Chile 
formas de vida deberían ser privilegiadas en desmedro de otras, reivindicando la objeción que calificaba al liberalismo de un credo combatiente. Solo sabemos que la balanza se inclinará inevitablemente a favor de una identidad, permaneciendo indeterminados los criterios para alcanzar dicha forma de vida.

Precisamente, este deslizamiento desde la neutralidad de la política del reconocimiento hacia la necesidad de contener un test de privilegio y reproche respecto de ciertas identidades, se agudiza por el escenario conflictivo en que efectivamente se sitúan los problemas del reconocimiento. Si bien en Taylor se promueve un horizonte de convivencia pacífica entre los agentes y sus culturas, esa aspiración descansa en una necesaria simetría distributiva de los bienes y derechos entre los integrantes de la comunidad. De lo contrario, si existen problemas de justicia, el conflicto deviene inevitable y la política de la autenticidad de Taylor no se encuentra capacitada para dirimirlos porque, en realidad, "[l] as reivindicaciones de autenticidad presuponen reivindicaciones de justicia"22. Bajo tales observaciones, el conflicto es pragmáticamente inevitable y, a su vez, la política del reconocimiento de Taylor pecaría de ingenua.

Desde esta línea argumentativa, Nancy Fraser ha puesto sobre la mesa la ceguera y unilateralidad del argumento político de la política del reconocimiento de Taylor. La filosofía de la política ha construido paradigmas explicativos a partir de las nociones de redistribución y reconocimiento. Pero el diseño del debate ha sugerido erróneamente la fractura entre ambas discusiones. Mientras la redistribución aludiría a una problemática de la tradición liberal asociada a la redistribución económica, el reconocimiento inspira la recuperación de las intuiciones hegelianas sobre la subjetividad relativas a la relación recíproca entre sujetos que están tanto unidos como separados entre sí. Fraser, en cambio, sugiere que tal distinción consiste en una falsa antítesis, dado que ambas nociones informan los conflictos sociales por consideraciones de justicia que son parte del escenario contemporáneo. Si bien “[...] la política de la redistribución suele equipararse a la política de clase, mientras que la política del reconocimiento se asimila a la "política de

22. Ibíd. Pág. 107.

Facultad de Derecho y Ciencias Sociales - Universidad de Valparaíso - Chile 
la identidad", a su vez asimiladas a luchas sobre el género, sexualidad, nacionalidad y carácter ético, dicha asociación es producto de una malinterpretación ${ }^{23}$. El riesgo de su adopción radica en disolver la pluralidad de reivindicaciones que conviven en el problema del reconocimiento bajo una sola modalidad; a saber, las reivindicaciones relativas a la especificidad del grupo.

Un enfoque que promueva la escisión entre los términos redistribución y reconocimiento se encuentra incapacitado no sólo para dar cuenta de la diversidad de modalidades que se agrupan bajo el paradigma del reconocimiento, sino también de hacer justicia a la relevancia propiamente política del debate. Detrás de cada movimiento de demanda social subyacen expresiones de justicia social que reclaman tanto consideraciones de reconocimiento como redistributivas. Aquello ocurre con el género que para Fraser es una diferencia social bidimensional, ya que no constituye “[...] una simple clase ni un mero grupo de estatus, sino una categoría híbrida enraizada al mismo tiempo en la estructura económica y en el orden de estatus de la sociedad"24. Luego, un grupo que formule alegaciones de género, piensa la autora estadounidense, padece tanto de una mala redistribución como de un reconocimiento erróneo, siendo imposible remediar sus necesidades segregándolas, dado que necesitan de ambas. El género es una combinación entre clase social y estatus. Y el problema se agudiza al notar que la generalidad de las luchas sociales deviene en reclamos por justicia, participando de una demanda común de superación de la injusticia que los afecta, pero dicha superación requiere cubrir consideraciones tanto de reconocimiento como de redistribución.

Pues bien, ¿Taylor da cuenta de esta esfera redistributiva acerca del paradigma del reconocimiento? Ciertamente no, pero lo problemático radica precisamente al evidenciar que en la tesis de Taylor no es necesario advertir las exigencias de justicia política del

23. FRASER, Nancy: "La justicia social en la era de la política de identidad: redistribución, reconocimiento y participación”. En: Revista de Trabajo, No 6, 2008. Pág. 86.

24. Ibíd. Págs. 91-92.

Revista de Ciencias Sociales - Número 65 (2014) - Universidad de Valparáíso - ISSN 0716-7725-Valparaíso, Chile 
reconocimiento, porque el prisma de la política del reconocimiento esgrimida por Taylor carece de genuina política, en la medida que renuncia a los criterios de corrección entre las identidades privilegiadas respecto de las desplazadas por su discurso. De igual manera, y según se indicó con anterioridad, la fundamentación de la constitución recíproca de identidades en la red de interlocución existente en el ámbito intersubjetivo, impide tematizar al conflicto político que define a la lucha por el reconocimiento. El liberalismo comunitario de Taylor sensible a la dignidad de las particularidades se muestra estéril para dar cuenta de la dimensión de conflictividad que define a lo propiamente político. Adaptar al liberalismo a la diversidad de particularidades también puede justificar la proyección de ciertas críticas formuladas en torno a la argumentación liberal a esta versión más atenuada.

Tal objeción no es novedosa si la analizamos a la luz de la tradición liberal. Chantal Mouffe ha observado que el liberalismo importa una filosofía de la política sin política, en tanto evade los elementos definitorios de lo político, como ocurre con el "[...] conflicto, el antagonismo y la decisión" ${ }^{25}$. Del modo como operan las pretensiones del consenso racional en las argumentaciones rawlsianas y habermasianas, se desactiva el antagonismo potencial que es parte constituyente de las relaciones sociales. El engranaje de Taylor pese a formularse como un liberalismo corregido, reactiva las deficiencias del pensamiento liberal respecto a domesticar la hostilidad y neutralizar el antagonismo político. Una cuestión como la redistribución es ajena a la propuesta de Taylor porque excede a su ámbito de interés, como una facción del liberalismo evita el reconocimiento de la dimensión antagónica de lo político. De acuerdo a Mouffe, el liberalismo en sus diversas variantes, "[a] fuerza de querer privilegiar el ¿̇vivir conjuntamente, propio de la polis, dejando de lado el pólemos es decir, el antagonismo y el conflicto [...] se pierde la posibilidad de aprehender la especificidad de la política democrática" ${ }^{26}$. La redistribución es tan

25. MOUFFE, Chantal: El retorno de lo político. Comunidad, ciudadanía, pluralismo y democracia radical. Paidós, Barcelona, 1999. (Trad. Marco Aurelio Galmarini). Pág. 13.

26. Ibíd. Pág. 14. Ciertamente conviene suscribir con reservas la crítica de Mouffe. Es cierto que su observación no hace justicia con la diversidad de concepciones

Facultad de Derecho y Ciencias Sociales - Universidad de Valparaíso - Chile 
inevitable como el conflicto cuando estamos propiamente situados en lo político, pero el liberalismo se encuentra irremediablemente incapacitado para dar cuenta de manera adecuada del reconocimiento y de la redistribución en la cual aquella cobra su genuino sentido político $^{27}$.

Desde un orden distinto de aproximaciones, la gama de evaluaciones conceptuales pueden inaugurarse con la reformulación de la lucha por el reconocimiento que efectúa Axel Honneth, para cubrir una posible gramática general de los conflictos sociales. Si bien Taylor y Honneth comparten la influencia hegeliana en sus planteamientos sobre el reconocimiento, difieren en su interpretación. A diferencia de Taylor, Honneth identifica en los escritos del joven Hegel un esquema altamente conflictivo de la comprensión del reconocimiento, desplazando una identidad estática del problema. La lucha del reconocimiento supone tanto una pretensión de los agentes por el hecho de ser objeto del reconocimiento, como la necesaria posibilidad que un agente pudiere no ser objeto de tal reconocimiento, de modo que el reconocimiento contribuye a refinar la auto-comprensión que tiene la comunidad moral respecto de sí misma.

Sin embargo, en esta etapa temprana del pensamiento hegeliano se desmarca la esfera de la eticidad de la intersubjetividad que es esencial en la formación de nuestra identidad para el reconocimiento de Taylor. Según Honneth, "Hegel no capta el dominio de la acción del Estado,

y profundas escisiones que es posible detectar en la genéricamente denominada tradición liberal. Solo hago notar que el déficit de conflictividad de las propuestas liberales heredadas del constructivismo kantiano que denuncia Mouffe, constituye una dificultad para la tesis de Taylor, al situar al reconocimiento como un escenario de ineludibles antagonismos y disputas sociales y políticas.

27. Ahora bien, la fuerza apelativa del liberalismo no proviene de su pretensión por neutralizar el conflicto, sino en sus vacilaciones para compatibilizar la igualdad de dignidad y propia especificidad de los individuos y grupos colectivos. Como lo sugiere Juan Ormeño, tal tensión queda de manifiesto precisamente en la cuestión del reconocimiento ya que "[a]mbas líneas se juntan en el reconocimiento, pues, de la igual dignidad de los seres humanos y de la facultad que cada uno tiene de vivir una vida propia”. Véase, ORMEÑO, Juan: “Conflicto, convergencia y reconocimiento”. Ob. cit. Pág. 148.

Revista de Ciencias Sociales - Número 65 (2014) - Universidad de Valparáíso - ISSN 0716-7725-Valparáiso, Chile 
como se hubiera podido esperar, como el lugar de realización de relaciones de reconocimiento tales que al individuo en su singularidad histórico-vital le producen respeto" ${ }^{28}$. La dimensión ética se presenta como una forma de autorreflexión objetiva del Espíritu, ubicando en el lugar de las relaciones intersubjetivas un esquema monológico de las relaciones del propio sujeto con sus momentos de alienación. Bajo estos términos, la filosofía de la subjetividad del reconocimiento tayloriano se pone a prueba con las genuinas raíces hegelianas que Honneth advierte. La interacción social de cada persona debiere haber sido un horizonte programático para el Hegel temprano, pero su compromiso con la filosofía de la conciencia lo llevó a admitir que todo el proceso de formación de la realización del Espíritu debía radicarse únicamente en términos de su contenido material. El concepto intersubjetivo de identidad sobre el cual Taylor fundamenta su intuición no pudo tener cabida en este período de Hegel, ya que "[...] hubiera necesitado del presupuesto de un concepto intersubjetivo de "eticidad que, una vez que pasó a una filosofía de la conciencia, no podía tener a su disposición" ${ }^{29}$. Como lo sabemos, tal trabajo será efectuado en su decisiva obra de 1807, Fenomenología del espíritu ${ }^{30}$.

Amartya Sen puede servirnos para clausurar la evaluación crítica que he desarrollado sobre la conferencia de Taylor. Su línea argumentativa también es conceptual y se ajusta, en parte, a las consideraciones que se desarrollarán en la tercera sección. Sen formula un agudo examen a las tesis comunitarias, rechazando que las identidades colectivas reclamen la subordinación de las decisiones

28. HONNETH, Axel: La lucha por el reconocimiento. Por una gramática moral de los conflictos sociales. Crítica, Barcelona, 1997. (Trad. Manuel Ballestero). Pág. 80 .

29. Ibíd. Pág. 81.

30. Sobre los compromisos ontológicos de la teoría del reconocimiento en este crucial texto de Hegel, puede consultarse QUANTE, Michael: "El reconocimiento como principio ontológico en la Fenomenología del espíritu de Hegel” (trad. Pola Iriarte). En: Lemm, Vanessa y Ormeño, Juan (eds.): Hegel, pensador de la actualidad. Universidad Diego Portales, Santiago de Chile, 2010. Págs. 141-162.

Facultad de Derecho y Ciencias Sociales - Universidad de Valparaíso - Chile 
individuales y la libertad personal desplegadas para formar la propia identidad. La reivindicación de Sen aboga por el privilegio de las múltiples elecciones que formulamos al momento de determinar nuestra identidad frente a identidades alternativas que se encuentran en competencia. Es una clave distinta a la adoptada por las concepciones comunitarias de la cuales Taylor forma parte. Bajo sus términos, se procura "[...] hacer de la identidad comunal definitiva un asunto de realización personal y no de elección" ${ }^{31}$. La identidad se entiende como un vínculo constitutivo de la comunidad que es descubierto por los agentes, pero no así elegido ni seleccionado. Sin embargo, difícilmente se podrán desplazar las elecciones racionales que a menudo los individuos realizan para definir su identidad, incluso en el marco del diálogo intersubjetivo al cual alude el argumento de Taylor. Aunque existan rasgos de nuestra identidad que sean efectivamente descubiertos, la identidad no es sólo una cuestión de descubrimiento, sino que siempre serán pertinentes cuestiones sustantivas de elección.

Ocultar las posibilidades de elección en la definición de la identidad acarrea dificultades respecto a la noción de responsabilidad. De acuerdo a Sen, “[h] ay algo profundamente debilitante en negar la posibilidad de elegir cuando esta existe, ya que equivale a una abdicación de la responsabilidad de considerar y valorar cómo debe uno pensar y con qué debe uno identificarse"32. La exclusión de la elección racional en materia de identidad equivale a extraviar nuestra agencia y responsabilidad en la propia constitución, conformándose con la creencia que la identidad solo puede descubrirse y no así tematizarse ${ }^{33}$.

31. SEN, Amartya: Reason before Identity. The Roman Lecture for 1998. Oxford University Press, Oxford, 1999. Pág. 15.

32. Ibíd. Pág. 21.

33. Esta doble dimensión de la propia identidad está advertida por Taylor al momento de cuestionar la visión negativa de la libertad, de raíces hobbesianas y respaldada por Berlin. Para el canadiense "[1] a libertad no puede ser la mera ausencia de obstáculos externos, porque también hay barreras internas. Y tampoco es posible limitar estas últimas a las que el sujeto identifica como tales, lo cual lo erigiría en el árbitro definitivo; en efecto, el sujeto puede estar profundamente equivocado con respecto a sus objetivos y a lo que quiere repudiar. Y de ser así, es menos capaz de

Revista de Ciencias Sociales - Número 65 (2014) - Universidad de Valparáíso - ISSN 0716-7725-Valparáiso, Chile 
Según se podrá apreciar, el entramado lingüístico intersubjetivo propuesto por Taylor, de un modo u otro, presupone un privilegio teórico respecto de las metas colectivas de supervivencia por sobre de las elecciones sustantivas que puedan ejercer los sujetos. Si bien las nociones de reconocimiento e identidad se van forjando dialógicamente, no es cristalino determinar si son meramente descubiertas en el horizonte de comunión cultural o efectivamente responden a decisiones de adjudicación que despliegan los agentes. El déficit de lo político que antes advertí en el argumento de Taylor transparenta que, al no existir criterios de delimitación entre formas de vida legítimas y no legítimas, junto con neutralizar el conflicto, difícilmente su política del reconocimiento reconocerá distintas alternativas de identidades que coexistan y se encuentren en un franco antagonismo, es decir, en plena disputa política. El sujeto se extravía bajo una multiplicidad de interlocuciones frente a las cuales carece de elección y en definitiva de responsabilidad en la constitución de su propia identidad. Precisamente, en la siguiente sección me ocuparé de la noción de responsabilidad.

\section{Reconocimiento y responsabilidad moral}

El amplio panorama de evaluaciones críticas que hemos revisado sobre la teoría del reconocimiento de Taylor, pudieren bastar para su abandono. Sin embargo, este ensayo es solo eso, un ensayo, y podría no hacer justicia a la filosofía desde la cual se despliegan las intuiciones de Taylor. En otro lugar, el autor canadiense efectuó una reconstrucción sobre la conformación de la identidad moderna ${ }^{34}$. Tal identidad se conformaría a partir de tres facetas: la interioridad humana asociada a la noción según la cual todos somos yos; la afirmación de la vida corriente desarrollada en la primera parte del período moderno; y la noción

libertad en el sentido significativo de la palabra”. Sobre este punto, véase TAYLOR, Charles: ¿Cuál es el problema de la libertad negativa? En: La libertad de los modernos. Amorrortu, Buenos Aires, 2005. (Trad. Horacio Pons). Pág. 280.

34. Un estudio sobre las conexiones entre las concepciones de modernidad e identidad en Charles Taylor en RUIZ, Carlos: "Modernidad e identidad en Charles Taylor”. En: Revista de Filosofía, Vol. 69, 2013. Págs. 227-243.

Facultad de Derecho y Ciencias Sociales - Universidad de Valparaíso - Chile 
expresivista de la naturaleza como la fuente de moralidad interior ${ }^{35}$. En el seno de la modernidad, piensa Taylor, se teje una peculiar conexión entre el yo y el espacio moral del cual forma parte. Los seres humanos vivimos nuestras vidas situados en horizontes intersubjetivos que operan como marcos referenciales, otorgándole sentido a nuestras existencias y prácticas cotidianas. La tesis del reconocimiento de Taylor encuentra también su significación bajo una filosofía de la subjetividad que a su vez considera decisivos a tales horizontes para la constitución de la acción humana. Para el yo moderno no es una simple cuestión contingente sobre la posibilidad de pensarse en términos desvinculados de los horizontes que lo rodean, porque aquello sería equivalente a transgredir la propia personalidad humana. La cuestión de la identidad se define necesariamente a partir de tales relaciones asociadas a las modalidades de interlocución lingüística.

La pregunta por la identidad resulta significativamente más compleja bajo el prisma moderno. La intensidad de la interrogante ¿quién soy yo? se devela al no poder respondérsele solo en términos de nombres y biografías. Al respecto, las observaciones de Taylor son clarificadoras: "[s]aber quién soy es como conocer dónde me

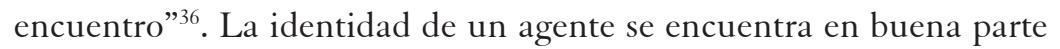
definida por la red de compromisos bajo los cuales aquel participa, de modo que a partir de tales relaciones el sujeto reconoce el significado de las cosas. Existe un vínculo entre la identidad de un sujeto y su orientación en el espacio moral, toda vez que saber quién uno es, implica estar orientado bajo un escenario asociado a cuestiones sobre lo correcto e incorrecto.

La definición del yo moderno es una decisión normativa desplegada bajo el contexto del cual aquel forma parte y que de igual modo constituye su identidad. De ahí que pensar a la identidad en clave moderna deviene ininteligible para un intérprete pre-moderno. Bajo la modernidad, la identidad personal se define a partir de una

35. TAYLOR, Charles: Fuentes del yo. La construcción de la identidad moderna. Paidós, Barcelona, 1996. (Trad. Ana Lizón). Pág. 12.

36. Ibíd. Pág. 43. Cursivas mías.

Revista de Ciencias Sociales - Número 65 (2014) - Universidad de Valparaíso - ISSN 0716-7725-Valparaíso, Chile 
sociedad de interlocutores rodeados de un complejo de horizontes, dentro de los cuales sabemos dónde estamos y qué significan las cosas para nosotros. En términos de Taylor, "[m]i identidad se define por los compromisos e identificaciones que proporcionan el marco u horizonte dentro del cual yo intento determinar, caso a caso, lo que es bueno, valioso, lo que se debe hacer, lo que apruebo o a lo que me opongo. En otras palabras, es el horizonte dentro del cual puedo adoptar una postura" 37 .

Desde esta perspectiva, por ejemplo, las críticas que Sen formulaba a las tesis comunitarias podrían no dar en el clavo en relación a Taylor. Una filosofía de la subjetividad moderna, como la articulada por Taylor, es tributaria de la elección de los marcos u horizontes bajo los cuales la identidad del agente cobra sentido. De igual manera, el yo moderno se sitúa bajo un escenario ético en que el agente se define sobre la base de las cuestiones que considera como correctas e incorrectas, decidiendo sobre lo que vale la pena o no efectuar. Así, una interpretación que desplace la subjetividad y el potencial de la elección en Taylor podría no ser genuinamente apropiada.

Una cuestión distinta ocurre con la noción de responsabilidad moral. Dicha noción podría brindar algunas luces acerca de la pertinencia de robustecer a la noción de reconocimiento con una de carácter normativo y constituyente de la identidad humana, como lo es la aptitud de un agente para ser moralmente responsable de sus acciones. Según se analizó con anterioridad, de acuerdo a Taylor, la identidad moderna se formaba mediante el complejo lingüístico de interlocutores que dialógicamente tenían lugar en el marco referencial bajo el cual se apoyaban sus prácticas, pero tal entramado lingüístico carecía de un sustrato genuinamente normativo para diferenciar entre identidades privilegiadas respecto de identidades alternativas desplazadas. Vale la pena asumir que si no existe definición de la identidad de manera monológica, ningún yo puede modernamente comprenderse a sí mismo, sin saber dónde se encuentra y qué desea responder. De modo que la pregunta por la identidad de un interlocutor requiere de otros interlocutores. El reconocimiento solo tiene sentido ahí donde las cosas

37. Ídem.

Facultad de Derecho y Ciencias Sociales - Universidad de Valparaíso - Chile 
gozan de significado para sus agentes. No obstante, ¿̇solo está en juego la efectiva ubicación lingüística de un agente bajo un contexto intersubjetivo? 38

Sostengo que la competencia para desplegar la interlocución en Taylor evade la cuestión de fondo; a saber, la noción de responsabilidad moral $^{39}$. Tal término puede servir de insumo moral a la tesis del reconocimiento, cuando no incluso conceptualmente reemplazarlo. Bajo la red de interlocución dialógica, la competencia se sigue de la capacidad para responder por sí mismo a la pregunta sobre ¿̇quién eres?, es decir, para "[...] ser un interlocutor entre otros, alguien que posee su propio punto de vista o un papel que desempeñar y que puede hablar por sí mismo" ${ }^{40}$. Pero tal competencia comunicativa pudiere resultar

38. Según Taylor, el rasgo general de la vida humana que desea evocar en su planteamiento acerca de la autenticidad, “[...] es el de su carácter fundamentalmente dialógico. Nos convertimos en agentes humanos plenos, capaces de comprendernos a nosotros mismos, y por ello de definir una identidad por medio de nuestra adquisición de ricos lenguajes de expresión humana”. Al respecto, véase TAYLOR, Charles: La ética de la autenticidad. Ob. cit. Pág. 68. Cursivas del original. No obstante, el interés de Taylor pierde de vista el rol crucial que cumple nuestro lenguaje en la moralidad y juzgamiento de nuestras acciones. Las prácticas de aprobación y reprobación moral se expresan a través de enunciados lingüísticos que también desempeñan un ejercicio de auto-comprensión para los agentes. Otro elemento esencial de nuestra vida humana, tal y como la conocemos, radica en la creencia de la responsabilidad moral de los individuos, de modo que la pertinencia de las prácticas lingüísticas sobre la corrección e incorrección de las acciones que nutren al escenario moral, contribuyen a refinar la definición que articulamos de nosotros mismos, forjando una imagen más fiel a uno mismo.

39. Robert Pippin ha sugerido que la cuestión central que la teoría del reconocimiento de Hegel busca responder radicaría en indagar acerca de la naturaleza y posibilidad de nuestra libertad. No existe una conexión analítica entre los términos de libertad y responsabilidad moral, pero Pippin advierte con razón que a la discusión sobre el reconocimiento subyacen cuestiones cruciales de índole normativa. La relevancia de la libertad se manifiesta en términos de operar como el fundamento estándar sobre la vigencia de nuestra responsabilidad moral, dotando de legitimidad a las prácticas de aprobación y censura moral. En relación a la lectura de Pippin, véase PIPPIN, Robert: "What is the Question for which the Hegelian Theory of Recognition is the Answer?”. En: European Journal of Philosophy, 8 (2), 2000. Págs. 155-172.

40. TAYLOR, Charles: Fuentes del yo. La construcción de la identidad moderna. Ob. cit. Pág. 45.

Revista de Ciencias Sociales - Número 65 (2014) - Universidad de Valparáíso - ISSN 0716-7725-Valparaíso, Chile 
restringida frente a una visión genérica de la competencia moral, bajo la cual el agente sea moralmente responsable bajo un contexto de participación ${ }^{41}$. Un aspecto significativo del debate hasta aquí revisado radica en descuidar el potencial explicativo de la noción de responsabilidad moral para nuestra auto-comprensión de las relaciones interpersonales que a diario experimentamos. Esta noción desempeña la función hermenéutica que resguarda el reconocimiento de identidades desde el prisma de Taylor, contribuyendo a nuestro ejercicio interpretativo acerca de quiénes somos, qué hacemos y cómo debiéremos actuar.

En este sentido, quisiere incorporar una herramienta conceptual articulada por P. F. Strawson para la evaluación de la relevancia de nuestras prácticas cotidianas de juzgamiento moral, bajo el marco del debate sobre el libre albedrío. El reconocimiento quizás no requiera examinar la relación entre la libertad y el determinismo, pero sí debiere procurar hacerse cargo de la responsabilidad moral, porque precisamente su déficit se expresa en la escasa normatividad de su propuesta. Bajo el marco de las transacciones morales bajo las cuales estamos situados, las relaciones respecto de los otros pueden tematizarse según las actitudes que adoptemos frente a los demás. Si frente a las acciones de los demás, reaccionamos con resentimiento o gratitud hacia sus autores, dada la mala o buena voluntad que se desprenden de sus acciones, estamos en medio de relaciones intersubjetivas de participación, denominadas actitudes reactivas ${ }^{42}$.

41. Respecto a la comprensión de la responsabilidad en términos de una competencia de los agentes para formar parte de contextos interpersonales de participación moral, bajo las cuales los sentimientos de gratitud y resentimientos resulten apropiados, véase PEREIRA Fredes, Esteban: "Contextos de participación como fundamento de la responsabilidad”. En: Orellana Benado, M. E. (comp.): Causas perdidas. Ensayos de filosofía jurídica, política y moral. Catalonia, Santiago de Chile, 2010. Págs. 307-331.

42. El contraste entre el tipo de actitudes que adoptamos hacia los demás, sean reactivas u objetivas, se sigue respectivamente de la participación o distancia de estos en contextos intersubjetivos. Tal como ocurre con el reconocimiento. De modo que sentimientos como el resentimiento y la gratitud reflejados en nuestras prácticas lingüísticas cotidianas, corresponden a "[...] la gama de actitudes y sentimientos

Facultad de Derecho y Ciencias Sociales - Universidad de Valparaíso - Chile 
En cambio, si el agente se encuentra al margen de nuestros sentimientos morales de resentimiento o gratitud, el sujeto objeto de la evaluación es desplazado de la comunidad moral, pudiendo ser considerado como un sujeto de táctica social o medidas preventivas, pero no como un sujeto moralmente responsable. Tales son las actitudes objetivas. En estos términos, un agente moralmente responsable equivale a ser un sujeto respecto al cual es apropiado experimentar tanto resentimiento como gratitud, reconociéndolo como parte de nuestras interacciones intersubjetivas propiamente morales ${ }^{43}$. Nuestras prácticas lingüísticas cotidianas, asociadas a las creencias más básicas que sustentamos, como lo es la legitimidad de las prácticas de aprobación y reprobación moral, transparentan que una parte constituyente de la identidad humana radica en su agencia y responsabilidad moral.

Si esto fuere así, una teoría del reconocimiento podría nutrirse normativamente con la inclusión de consideraciones relativas a la responsabilidad moral de los agentes. La noción de responsabilidad moral presupone la participación del agente bajo contextos de interacción y negociación moral y no únicamente bajo redes de conexión lingüística, y de ahí que resulte válido experimentar sentimientos propiamente morales en base a su accionar. Pero la configuración de la responsabilidad moral se muestra más flexible con las dimensiones políticas y redistributivas que según lo indiqué la tesis del reconocimiento, o a lo menos bajo el prisma de Taylor, no lograba satisfacer. No es descartable que gracias a este marco teórico bifronte sobre nuestras actitudes desarrolladas bajo el plano moral, pudiéremos obtener rendimientos explicativos en los asuntos públicos, escenario representado por su ineludible conflictividad. Es en tal lugar donde efectivamente se encuentran los agentes.

La generalidad de los conflictos sociales se produce por la existencia de demandas por necesidades básicas insatisfechas. Pero, de

reactivos que son propias del compromiso y la participación en relaciones humanas interpersonales con otros [...]. Véase, STRAWSON, P. F.: "Libertad y resentimiento". En: Libertad y resentimiento y otros ensayos. Paidós, Barcelona, 1995. (Trad. Juan José Acero). Pág. 47.

43. Ibíd. Págs. 53-57.

Revista de Ciencias Sociales - Número 65 (2014) - Universidad de Valparaíso - ISSN 0716-7725-Valparaíso, Chile 
igual modo, expresan dimensiones de reacción frente a la objetivización que sufren los agentes o grupos sociales en los asuntos públicos ${ }^{44}$. Puede ser que detrás la demanda de reconocimiento en la esfera privada, el sujeto solo apele a su identidad en tanto agente moralmente responsable, pero bajo el ámbito público las alegaciones de reconocimiento, pueden ser también interpretadas como manifestaciones de disconformidad hacia ciertas políticas institucionales que progresivamente han provocado su desplazamiento mediante modalidades de actitudes objetivas. Tales medidas son adoptadas hacia ciertos grupos para socavar su influencia en las decisiones públicas y responden en lo social al esquema presentado a través de Strawson.

La responsabilidad moral asociada a la participación de un agente y un grupo social en complejos intersubjetivos da cuenta de esferas normativas y, asimismo, políticas del reconocimiento ${ }^{45}$. Frente a la sistemática ausencia de respuestas efectivas para la ciudadanía, su resentimiento hacia los poderes políticos admite interpretársele como alegaciones por su reconocimiento. No se trata sólo de una cuestión de identidad, sino de vigencia en los asuntos públicos. Después de todo, el

44. De acuerdo a Axel Honneth, ciertos debates económicos pertenecen constitutivamente a la lucha por el reconocimiento, manifestándose cuando los “[...] movimientos sociales [pretenden] llamar la atención de la opinión pública sobre la significación desdeñada de las cualidades y capacidades colectivamente representadas por ellos [...]". HONNETH, Axel: La lucha por el reconocimiento. Por una gramática moral de los conflictos sociales. Ob. cit. Pág. 156.

45. Más allá de su influyente ensayo de 1994, Taylor tampoco se muestra absolutamente silente frente estas dimensiones asociadas al reconocimiento. Dichas consideraciones se transparentan al detenerse en la vinculación que él denuncia entre la fragmentación del atomismo metodológico con la falta de identificación de los individuos con su comunidad política, generando una cierta impotencia política. Según Taylor, “[u]na identidad política que se apaga hace más difícil la movilización eficaz y una sensación de desamparo engendra la alienación”. TAYLOR, Charles: Argumentos filosóficos. Ensayos sobre el conocimiento, el lenguaje y la modernidad. Ob. cit. Pág. 369. Así, la autoafirmación que efectúa un grupo social en el ámbito público a través de sus demandas van de la mano en relación a sus exigencias de reconocimiento en el plano intersubjetivo. De modo que "[l]a acción común exitosa puede conllevar una sensación de autorización y de identificación de refuerzo con la comunidad política”. Véase, Ibíd. Pág. 370.

Facultad de Derecho y Ciencias Sociales - Universidad de Valparaíso - Chile 
resentimiento únicamente es operativo ahí donde existe una verdadera participación intersubjetiva. Al ser desplazados de la comunidad moral en la cual se definen y desenvuelven sus planes individuales y colectivos de vida, difícilmente podrán conformarse con su identidad lingüística. Tales observaciones surgen de un ejercicio de auto-comprensión, forjando una imagen de lo humano que es condición necesaria de nuestra constitución, como agentes situados en contextos de participación moral.

El término reconocimiento, aún en la versión liberal-comunitaria de Taylor, es ingenuo con la intensidad del conflicto político, desatendiendo sus dimensiones normativas y redistributivas. Repensar a la teoría del reconocimiento a la luz de la responsabilidad moral facilita la inserción del acto de reconocernos en el escenario bajo el cual se sitúa, es decir, aquel donde las identidades no sólo se configuran lingüísticamente, sino que además forman parte de demandas y exigencias sociales para resolver sus necesidades materiales. La responsabilidad moral entendida en términos de actitudes reactivas de participación es flexible frente a esta clase de consideraciones. De manera tal que conviene recuperar el sentido relevante de hablar de una lucha por el reconocimiento y no solo por resultar reconocido en aquel acto ${ }^{46}$. En el reconocimiento no debiere importar tanto lo reconocido, sino la justificación del por qué es razonable que opere tal reconocimiento. No debemos perder de vista que tanto los agentes individuales como

46. Difícilmente sería acertado afirmar que la esterilidad de la teoría tayloriana sobre el reconocimiento para cubrir los conflictos morales, políticos y redistributivos, es de igual modo imputable a la teoría de Honneth. En efecto, aquella versa sobre la lucha por el reconocimiento y su espectro de consideraciones es bastante amplio, de ahí que, por ejemplo, “[...] la resistencia colectiva, que brota de la interpretación crítico-social de sentimientos de menosprecio compartidos en común, no es sólo un medio práctico de reivindicar para el futuro un modelo ampliado de reconocimiento". HONNETH, Axel: La lucha por el reconocimiento. Por una gramática moral de los conflictos sociales. Ob. cit. Pág. 198. El problema que enfrenta Honneth es distinto. Los diversos tópicos tratados a propósito de su lucha por el reconocimiento dan cuenta más bien de la experiencia del reconocimiento, debilitando la especificidad de la teoría del reconocimiento como ejercicio de auto-comprensión y, asimismo, descuidando la importancia de la noción de responsabilidad moral en las relaciones situadas bajo la comunidad social.

Revista de Ciencias Sociales - Número 65 (2014) - Universidad de Valparáíso - ISSN 0716-7725-Valparaíso, Chile 
los grupos colectivos, buscan confirmar su participación en contextos morales y públicos, ratificando su agencia y dignidad tanto privada como pública. Aquello que desde temprano estuvo en juego al momento de discutir modernamente acerca de nuestra identidad ${ }^{47}$.

\section{Conclusiones}

Si las precedentes consideraciones fueren correctas, la disputa por el reconocimiento develaría genuinos reclamos de disconformidad de los individuos por su falta de inclusión en el espacio público, y el resentimiento tiene mucho que decir frente a las actitudes de objetivización que sufren quienes son desplazados de aquel. La adopción de las actitudes objetivas suspende la pertinencia de las actitudes reactivas de participación hacia estos grupos sociales que despliegan sus intereses bajo un conjunto de legítimas demandas. En buenas cuentas, ya no se les sigue considerando miembros de la comunidad moral y política. La exclusión de individuos y grupos de las decisiones públicas expresa un déficit de reconocimiento que atenta contra la identidad de aquellos y, asimismo, transgrede uno de los aspectos más básicos de la vida humana; a saber, la vigencia de nuestras relaciones interpersonales de participación sostenidas en base a la responsabilidad moral de los agentes. Esta intuición emana al aceptar

47. De manera seminal, Johann Gottlieb Fitche sostuvo que el concepto de individualidad es un concepto recíproco, solo pudiendo pensarse en relación con otro pensar y, a su vez, encontrándose condicionado por la forma de ese pensar. Y a partir del concepto dado se determina una comunidad, de modo que las consecuencias posteriores ya no sólo dependen del agente racional, sino también de quien por aquel ha entrado consigo en comunidad. Existe una obligación normativa recíproca, obligándose cada uno a tratarse de igual forma en virtud de su reconocimiento. De ahí que Fitche observe con razón que "[...] el concepto es necesario, y esta necesidad nos fuerza a ambos a atenernos a él y a sus consecuencias necesarias: los dos estamos vinculados y obligados el uno al otro por nuestra existencia". FICHTE, J.G.: Fundamento del derecho natural según los principios de la Doctrina de la ciencia. Centro de Estudios Constitucionales, Madrid, 1994. (Trad. J. L. Villacañas Berlanga, Faustino Oncina Coves y Manuel Ramos Valera). Pág. 140. Cursivas del original. Es evidente que las exigencias normativas derivadas del reconocimiento se siguen de nuestra entrada y participación en una comunidad común.

Facultad de Derecho y Ciencias Sociales - Universidad de Valparaíso - Chile 
que la teoría del reconocimiento importa un ejercicio de auto-reflexión que nos indica quiénes somos, dónde estamos y qué hacemos en nuestras vidas. Ahí radican los compromisos y horizontes que definen nuestra identidad y que a diario experimentamos.

El ensayo de Charles Taylor es ciertamente decisivo en las recientes discusiones sobre las nociones de identidad y reconocimiento. Desde luego, muchos de los cuestionamientos esgrimidos en torno a The Politics of Recognition han identificado correctamente las dificultades que enfrenta la propuesta tayloriana. No obstante lo cual, un análisis individual de este texto podría descuidar elementos centrales de la filosofía del autor canadiense, extraviando la conexión existente entre sus estudios respecto a la identidad, el reconocimiento y el ideal ético de la autenticidad, bajo el contexto del espacio moral de la modernidad. Pero aun cuando logremos sortear las vallas de su teoría del reconocimiento, las exigencias normativas y redistributivas vigentes en los conflictos políticos sobre el reconocimiento de formas de vida, permanecerán sin una definitiva clausura explicativa. De ahí que la noción de responsabilidad moral pueda contribuir a poner de relieve lo verdaderamente importante de esta teoría, esto es, nuestra efectiva participación en contextos intersubjetivos de transacción moral en los asuntos privados y públicos. Su conexión con las actitudes reactivas que gobiernan el juzgamiento de nuestras acciones y legitiman el compromiso en contextos de participación social, provee a la teoría del reconocimiento de las dimensiones normativas y redistributivas que su diseño original carecía. Las disputas por el reconocimiento constituyen conflictos relativos a la búsqueda de satisfacción de necesidades básicas, tal como la efectiva participación de los agentes y grupos en las decisiones políticas, reafirmando su agencia y competencia moral en el conjunto de relaciones sociales.

Por supuesto, no es necesario advertir que no existe una relación analítica entre los términos de reconocimiento y responsabilidad moral. El esfuerzo interpretativo consistió en examinar a la teoría del reconocimiento a partir de las exigencias de la responsabilidad moral en los planos interpersonales, develando que esta última noción puede cumplir un desempeño explicativo asociado a la distinción entre actitudes reactivas de participación y actitudes objetivas de distancia o

Revista de Ciencias Sociales - Número 65 (2014) - Universidad de Valparaíso - ISSN 0716-7725-Valparaíso, Chile 
exclusión social. Esto permite suministrar estándares normativos indispensables en la discusión sobre el reconocimiento, dotando a la pretendida política del reconocimiento de elementos que permitan hacerse cargo de los conflictos políticos suscitados entre las distintas identidades. Así concebida la reformulación del problema, la política del reconocimiento recuperaría su lugar en lo político y la normatividad se alza como el fundamento de la vinculación interpersonal, bajo la cual tiene significado propender hacia un reconocimiento que permita la constitución de la identidad de un yo moralmente responsable y, a su vez, como un participante social plenamente activo en la disputa antagónica que define al escenario político contemporáneo.

\section{BIBLIOGRAFÍA}

BENHABIB, Seyla: “¿De la redistribución al reconocimiento? El cambio de paradigma de la política contemporánea”. En: Las Reivindicaciones de la Cultura. Igualdad y diversidad en la era global (trad. Alejandra Vassallo). Katz, Madrid, 2006. Págs. 94-144.

CORREA, Matías: "Sobre Charles Taylor y algunos problemas relativos a la política del reconocimiento". En: Ars Boni et Aequi, $\mathrm{N}^{\circ} 5$, 2009. Págs. 157-182.

FICHTE, J.G.: Fundamento del derecho natural según los principios de la Doctrina de la ciencia (trad. J. L. Villacañas Berlanga, Faustino

Oncina Coves y Manuel Ramos Valera). Centro de Estudios Constitucionales, Madrid, 1994.

FRASER, Nancy: "La justicia social en la era de la política de identidad: redistribución, reconocimiento y participación”. En: Revista de Trabajo, No 6, 2008. Págs. 83-99.

HABERMAS, Jürgen: Teoría de la acción comunicativa. Tomo I. Racionalidad de la acción y racionalización social (trad. Manuel Jiménez

Redondo). Taurus, Madrid, 1987.

HONNETH, Axel: La lucha por el reconocimiento. Por una gramática moral de los conflictos sociales (trad. Manuel Ballestero). Crítica, Barcelona, 1997.

IKÄHEIMO, Heikki y \& LAITINEN, Arto (eds.): Recognition and Social Ontology. Brill, Leiden-Boston, 2011.

Facultad de Derecho y Ciencias Sociales - Universidad de Valparaíso - Chile 
Reconocimiento y responsabilidad moral. A propósito de la teoría...

KANT, Immanuel: Fundamentación para una metafísica de las costumbres (trad. Roberto Rodríguez Aramayo). Alianza, Madrid, 2002.

MOUFFE, Chantal: El retorno de lo político. Comunidad, ciudadanía, pluralismo y democracia radical (trad. Marco Aurelio Galmarini).

Paidós, Barcelona, 1999.

ORELLANA Benado, M. E.: "Tradiciones y concepciones en filosofía”. En: Nudler, Oscar (ed.): Filosofía de la filosofía. Enciclopedia

Iberoamericana de Filosofía, No 31. Trotta, Madrid, 2010. Págs. 49-78.

ORMEÑO, Juan: "Conflicto, convergencia y reconocimiento". En: Revista Laguna, No 16, 2005. Págs. 145-154.

PEREIRA Fredes, Esteban: "Contextos de participación como fundamento de la responsabilidad". En: Orellana Benado, M. E.

(comp.): Causas perdidas. Ensayos de filosofía jurídica, política y moral. Catalonia, Santiago de Chile, 2010. Págs. 307-331.

PIPPIN, Robert: "What is the Question for which the Hegelian Theory of Recognition is the Answer?". En: European Journal of

Philosophy, 8 (2), 2000. Págs.155-172.

QUANTE, Michael: "El reconocimiento como principio ontológico en la Fenomenología del espíritu de Hegel" (trad. Pola Iriarte). En:

Lemm, Vanessa y Ormeño, Juan (eds.): Hegel, pensador de la actualidad.

Universidad Diego Portales, Santiago de Chile, 2010. Págs. 141-162.

RUIZ, Carlos: "Modernidad e identidad en Charles Taylor". En: Revista de Filosofía, Vol. 69, 2013. Págs. 227-243.

SEN, Amartya: Reason before Identity. The Roman Lecture for 1998. Oxford University Press, Oxford, 1999.

SCHMIDT am Busch, Hans-Christoph y ZURN, Christopher F. (eds.): The Philosophy of Recognition: Historical and Contemporary

Perspectives. Lexington Books, Plymouth, 2010.

STRAWSON, P. F.: "Libertad y resentimiento". En: Libertad y resentimiento y otros ensayos (trad. Juan José Acero). Paidós, Barcelona, 1995. Págs. 37-67.

TAYLOR, Charles: ¿Cuál es el problema de la libertad negativa? En: La libertad de los modernos (trad. Horacio Pons). Amorrortu, Buenos Aires, 2005. Págs. 257-281.

TAYLOR, Charles: El multiculturalismo y "la política del reconocimiento" (trad. Mónica Utrilla de Neira). Fondo de Cultura Económica, México D.F., 2003. Págs. 53-116.

Revista de Ciencias Sociales - Número 65 (2014) - Universidad de Valparáíso - ISSN 0716-7725-Valparaíso, Chile 
TAYLOR, Charles: Argumentos filosóficos. Ensayos sobre el conocimiento, el lenguaje y la modernidad (trad. Fina Birulés Bertrán). Paidós, Barcelona, 1997.

TAYLOR, Charles: Fuentes del yo. La construcción de la identidad moderna (trad. Ana Lizón). Paidós, Barcelona, 1996.

TAYLOR, Charles: La ética de la autenticidad (trad. Pablo Carbajosa Pérez). Paidós, Barcelona, 1994.

WALZER, Michael: "Comentario”. En: Taylor, Charles: El multiculturalismo y "la política del reconocimiento" (trad. Mónica Utrilla

de Neira). Fondo de Cultura Económica, México D.F., 2003. Págs. 135149.

Facultad de Derecho y Ciencias Sociales - Universidad de Valparaíso - Chile 